\title{
Exercise and Eating Habits in Relation to BMI in Female College Students of Almareefa Colleges in Ad Diriyah
}

\author{
Nour Taher Nasr*, Ahad Abdullah Alqahtani, Baraah Ali Alkahmous, Jumanah Essam Abu Jamea, Mooj \\ Abdullah Alghofaili, Dr. Mouna Hassan, Nada Hasanin Abdulmalik, Roaa Essam Abu Jamea, Roula \\ Hadyan AlHadyan, Shireen Jaffar Al-Shami and Wala Ahmed Abdulkarim
}

College of Medicine, Almaarefa Colleges for Science and Technology, Riyadh, Saudi Arabia

${ }^{*}$ Corresponding author: Nour Taher Nasr, College of Medicine, Almaarefa Colleges for Science and Technology, Riyadh, Saudi Arabia, E-mail: nour.t.nasr@gmail.com

Citation: Nour Taher Nasr, Ahad Abdullah Alqahtani, Baraah Ali Alkahmous, Jumanah Essam Abu Jamea, Mooj Abdullah Alghofaili, et al. (2018) Exercise and Eating Habits in Relation to BMI in Female College Students of Almareefa Colleges in Ad Diriyah. J Obes Overweig 4(1): 103. doi: 10.15744/2455-7633.4.103. doi: 10.15744/24557633.4.103

Received Date: January 08, 2018 Accepted Date: May 24, 2018 Published Date: May 26, 2018

\begin{abstract}
Introduction: The benefits of exercise have been known a long time ago, physical activity is an important factor to reduce the risk of unhealthy weigh. Certain types of foods, eating habits have been linked to weight and BMI.

Objectives: The purpose of the study was to identify the relationship between exercise, eating habits and BMI.

Methods: This was an observational descriptive cross-sectional university-based study of 100 female medical students of Almaarefa Colleges from level 3 to 8, participants were chosen randomly and questionnaires were distributed among them and anthropometric measurements were taken for BMI calculations.

Results: Out of 100 female medical students, $52 \%$ were of a normal weight category at level 5-6. Obesity was only seen among level 3-4 (12\%).57\% of normal weight participants don't eat very fast. $52 \%$ of normal weight participants exercise and $35 \%$ of them exercise 3 times or more a week. No obese participants were seen in those who exercise 3 times a week or more. $60 \%$ of overweight/obese participants exercise 2 times or less a week.

Conclusion: This study revealed a strong association between physical activity and BMI, also fast eating was found to be associated with obesity.

Keywords: Obesity; Physical activity; Eating habits
\end{abstract}

\section{Introduction}

Certain types of foods and eating habits have been linked to weight and BMI, Physical activity and physical fitness are important factors in reducing the risk of unhealthy weight gain and related illnesses, and moderate to high fitness brings about health benefits.

The BMI is a statistical measurement derived from the height and weight. It's an inexpensive and easy to perform method of screening for weight categories that may lead to health problems. It does not measure the percentage of body fat.

The BMI measurement can sometimes be misleading, a muscle woman may have a high BMI but have much less fat than an unfit woman whose BMI is lower. However, knowing what a healthy BMI can help in setting a realistic and appropriate weight goal.

The benefits of exercise have been known a long time ago. Marcus Cicero around 65 BC, stated: "It is exercise alone that supports the spirit, and keeps the mind in vigor". However, the link between physical health and exercise (or the lack of it) was discovered later, and reported by a team led by Jerry Morris. Doctor Morris noted that men of similar social class and occupation had markedly different rates of heart attack, depending on the level of exercise they got. This link had not previously noted and was later confirmed by other researchers.

The term eating habits or food habits refers to why and how people eat, which foods they eat, and with whom they eat, as well as the ways people obtain, store, use, and discard food.

Individual, social, cultural, religious, economic, environmental and political factors all influence people's eating habits. 
Objectives

- To measure the proportion of overweight and obese female students.

- To measure the proportion of female college students who practice exercise.

- To measure the proportion of female college students who have good eating habits.

- To find out the relationship between physical activitiy, eating habits and BMI.

\section{Literature review}

The increase in overweight and obesity levels in the past decades shows an urgent need for a better understanding of its causes across the lifespan. Research on balancing energy intake and expenditure through adequate nutrition and physical activity (PA) habits can be considered as a primary focus in this understanding. Minor changes in food intake and PA can have sizeable effects on body weight and obesity. However, it is less clear which specific diet and PA patterns contribute to the risk of weight gain in specific populations.

A study conducted by Chauhan published in 2014, India, titled Association between eating habits and body mass index (BMI) of adolescents. This study aimed to measure and to assess the eating habits and BMI among adolescents, the purpose was to find the correlation between eating habits and (BMI) of adolescents. It was done choosing a sample of 150 adolescents aged 14-15 years. The majority of the adolescent had healthy eating habits. The final result showed that there was no correlation between BMI and eating habit. There was also a low prevalence of unhealthy eating habits, obesity, and overweight according to the study [1].

A Cross-Sectional study conducted by Gunes in 2012, Turkey, titled The relation between eating habits and a high BMI among freshman students, aimed to study the relation between eating habits and a high (BMI) in first-year freshman university students and included 2525 students 18 to 22 years old from a Turkish population. According to the result, $17 \%$ were overweight or obese. After analyses, it was identified that male gender, recent weight change, and the high number of meals are independent predictors of obesity/ overweight. Frequent consumptions of beer, alcoholic drinks other than wine (e.g., spirits including whisky, gin, raki, vodka), coffee, tea, coke, red meat, variety meat, and eggs were associated with a significantly higher risk of obesity/overweight, whereas frequent consumption of snacks was associated with a low risk of obesity/overweight [2].

A study was conducted in 2010 by Al- Rethaiaa, Obesity and eating habits among college students in Saudi Arabia. It was done on a sample of 357 male students aged 18-24 from a college in Al-Qassim city. The aim was to identify the prevalence of overweight and obesity in the sample and to determine the relationship between the students' body weight status and composition and their eating habits. The result clearly showed that $15.7 \%$ of the students were obese and $21.8 \%$ were overweight. The most popular eating habits that noticed were having two meals per day including breakfast, eating with family, together with frequent snacks and fried food consumption [3].

A study conducted by Alfawaz in Riyadh in 2012 on the relationship between fast food consumption and BMI among university female students. The study aim was to understand the relationship between (BMI) and the pattern of consumption of fast food. Fast food consumption frequency of 1-2 times per week was high among them, and there was no significant relationship between BMI and the pattern of consumption of fast food. According to the data, $25 \%$ of female students were overweight and obese. However, the frequency of fast food consumption was high among students [4].

Also, a Tongan study was conducted in 2000 by Smith, Body mass index, physical activity and dietary behaviors among adolescents in the Kingdom of Tonga. The study was aiming to compare the prevalence of overweight and obesity among adolescents by using international and ethnic-specific cut-off points and to examine patterns of PA and dietary behavior on a sample of 443 school students. The result showed that PA participation was the only behavior independently associated with a lower risk of overweight or obesity [5].

Another study titled A Survey of Dietary and Exercise Habits and Perceived Barriers to Following a Healthy Lifestyle in a College Population was done by Silliman in 2002. It was done to assess the diet and exercise habits and perceived barriers that could impede following a healthy lifestyle of college students, as well as determining if differences exist by gender. The survey was conducted among 471 college students, USA. $25 \%$ of students were found to be overweight and $6 \%$ were classified as obese. Most of the students didn't meet the minimum recommended intake of dietary fiber, fruits, and vegetables; and exceed recommended intakes of total fat and saturated fat, sugar, and sodium. Another significant finding was that men exercised more frequently and at a greater intensity than women and were more confident with their body image. The survey found that the most common barriers to exercise were lack of motivation, lack of time, and lack of willpower [6].

Another study titled Weight Changes, Exercise, and Dietary Patterns During Freshman and Sophomore Years of College was done by Racette in USA 2005, aimed to assess weight, exercise, and dietary patterns of 764 college students (women \& men) during freshman and sophomore years. The study concluded that lack of regular exercise, weight gain, and unhealthy eating patterns appeared to be common among students in the sample during the first 2 years of college [7].

Another study to determine the correlation of BMI to dietary intake, fitness level and eating and exercise attitudes of college students was done by James, 2010, USA, with a sample of 772 students between the ages of 18-25 between the years of July 2004July 2009. The adequacy of diet for students who aged 20 years and younger was found to be correlated to their attitudes about food 
and body image. This was not true in the students who were 21 and older suggesting that the diet of the freshman and sophomore students were more impacted by negative eating attitudes. Results from the research also found that in the younger students, the adequacy of their diet was positively correlated to their attitudes about exercise whereas in the students 21 years old and older no correlation was found [8].

A study titled Variation in dietary intake and PA pattern as predictors of change in BMI Z-score among Brazilian adolescents 2004-2005, which was done by Enes and aimed to assess whether changes in dietary intake and PA pattern are associated with the annual BMI z-score change among adolescents. The study was conducted in public schools in Brazil (431 adolescents). Among variables related to PA pattern, only playing videogames and using computers were found to be increased over the year as well as the intake of fruits and vegetables and sugar-sweetened beverages. An increased consumption of fatty foods and sweetened natural fruit juices was positively associated with the rise in BMI z-score [9].

Another study titled Perceived and desired weight; weight related eating and exercising behaviors, among thin, overweight, obese or normal weight Australian children and adolescents was conducted in 2011 by O'Dea, in Australia. The sample included 8550 school children aged 6-18 years selected from every state and territory of Australia. The result of the study showed some distributions of weight status, and as a conclusion, both extremes of the spectrum of weight, from underweight to obese, may have serious health consequences for the individuals, as well as for public health policy [10].

To explore a relationship of PA and dietary habits with BMI in the transition from childhood to adolescence, a study was performed (Haerens, 2010, Belgium), in which the baseline sample consisted of children with the mean age of 10 years. For most of the dietary behaviors that were included in the study, no significant relationships appeared to be highly associated with BMI; on the other hand, there was a relation between higher BMI and skipping breakfast. Regarding PA, the frequency of sports participation played a substantial role in weight management, the results also showed that children with higher BMI are less likely to participate in sports activities due to their fears of teasing or because they are less athletic [11].

An Iranian study was conducted in 2003 which made by Kelishadi, Association of physical activity and dietary behaviors in relation to the body mass index (BMI) in a national sample of Iranian children and adolescents. It was a multicenter study performed among 21,111 school students and aimed to examine the relation of dietary and PA patterns with the BMI among the chosen sample. As a result, they found that fruit and vegetables, dairy products and snacks had a consumption of approximately twice a day. Regarding the PA level, it was significantly higher among boys than girls, in rural than in urban residents, and in intermediate students than high-school students. The study concluded that the unhealthy lifestyles make Iranian young people prone to chronic diseases later in life [12].

\section{Methods}

\section{Research design}

An observational descriptive cross-sectional university-based study design.

\section{Study area and population}

The study was conducted at Almaarefa Colleges for Science and Technology (MCST), Ad Diriyah, in Kingdom of Saudi Arabia; the colleges provide different specialties including: Medicine, Pharmacy and Applied Sciences (Nursing, Respiratory Therapy, Emergency Medical Services, Computer Science, and Information Systems).

\section{Sample size and technique}

The study covered a sample of 100 female medical students from level(3) to level(8) who were chosen randomly, each student had the same chance for participating, and those absent medical students from the chosen levels on that day were excluded from the study.

\section{Data needs}

For the purpose of meeting the research data needs, a questionnaire was thoughtfully designed and constructed to cover multiple aspects including questions about personal information, some questions regarding different eating habits and other about the frequency and intensity of the exercises practiced by the chosen sample. The validity and reliability of each question were checked and measured separately, and those which were found to be of a low significant were excluded accordingly. For anthropometric measurements, weight and height scale used.

\section{Data collection method}

The data was collected over one day as the pre-tested, pre-designed close-ended questionnaire which was constructed earlier was distributed randomly among a sample of 100 medical students from level 3 to level 8, and for those who accepted to participate and fill the questionnaire, the anthropometric measurements were taken for calculating their BMI. 


\section{Data analysis}

After data was gathered, it was cleared and then analyzed by SPSS. The results were presented in tables as frequencies and percentages. The chi-square of significance was used, and a p-value of $\leq 0.05$ was taken to be significant.

\section{Ethical consideration}

Before conducting the study a verbal consent was taken from each participating student, confidentiality of the data was promised and maintained.

\section{Results}

\section{Descriptive Statistics}

Out of 100 female medical students, 52\% were of a normal weight category at level 5-6. Obesity was only seen among level 3-4 (12\%).57\% of normal weight participants don't eat very fast. $52 \%$ of normal weight participants exercise and $35 \%$ of them exercise 3 times or more a week. No obese participants were seen in those who exercise 3 times a week or more. $60 \%$ of overweight/obese participants exercise 2 times or less a week.

$98 \%$ of the participants were from age group 20-24 and 42\% from level 5-6. 54\% have normal BMI. 66\% always- usually have breakfast. $70 \%$ always- usually eat fruits/vegetables. $49 \%$ of the participants have chips as a snack. $46 \%$ of the participants have sweets as a snack (Table 1.1).

\begin{tabular}{|c|c|c|c|}
\hline & & Frequency & $\operatorname{Pcrc}(\mathrm{nl}$ \\
\hline \multirow{2}{*}{ Age } & $20-24$ & 98 & 98.0 \\
\hline & $25-30$ & 2 & 2.0 \\
\hline \multirow{3}{*}{ Le,,$e l$} & $3-4$ & 26 & 26.0 \\
\hline & $5-6$ & 42 & 42.0 \\
\hline & $7-8$ & 32 & 32.0 \\
\hline \multirow{3}{*}{$\begin{array}{c}\text { Whel } \\
\text { Category } \\
\text { B M I }\end{array}$} & Underweight & 21 & 21.0 \\
\hline & Nonnal & 54 & 54.0 \\
\hline & Overweight/Obe.. & 25 & 25.0 \\
\hline \multirow{2}{*}{ Breakfast } & A lways_Usually & 66 & 66.0 \\
\hline & Rarely • Never & 34 & 34.0 \\
\hline \multirow{2}{*}{ M eab: } & $1-3$ & 94 & 94.0 \\
\hline & $4 \cdot 6$ & 6 & 6.0 \\
\hline \multirow{2}{*}{$\begin{array}{c}\text { Fruits } \\
\text { Veget ables }\end{array}$} & Always .Usuall y & 70 & 70.0 \\
\hline & Rarely Never & 30 & 30.0 \\
\hline \multirow{2}{*}{ Snacks } & Yes & 28 & 28.0 \\
\hline & No & 72 & 72.0 \\
\hline \multirow{2}{*}{ Chips } & Yes & 49 & 49.0 \\
\hline & No & 51 & 51.0 \\
\hline \multirow{2}{*}{$\mathrm{uL}<$} & Yes & 15 & 15.0 \\
\hline & No & 85 & 85.0 \\
\hline \multirow{2}{*}{ SWl't!ts } & Yes & 46 & 46.0 \\
\hline & No & 54 & 54.0 \\
\hline
\end{tabular}

Table 1.1 : Categorizing study sample into groups according to some given variables

$67 \%$ of the participants eat fast food weekly. $69 \%$ of the participants drink soda less than 3 times a week. $58 \%$ of the participants do exercise. $63 \%$ of the participants exercise 3 times a week or more (Table 1.2).

\begin{tabular}{|c|c|c|c|}
\hline \multirow{2}{*}{ FalFood } & Daily & 5 & 5.0 \\
\cline { 2 - 4 } & Weekly & 67 & 67.0 \\
\cline { 2 - 4 } & Monthly & 25 & 25.0 \\
\cline { 2 - 4 } & NCl’ef & 3 & 3.0 \\
\hline \multirow{2}{*}{ SodaJ } & 02 & 69 & 69.0 \\
\cline { 2 - 4 } & 3 & 31 & 31.0 \\
\hline \multirow{2}{*}{$\begin{array}{c}\text { F.alin nd } \\
\text { Emolions }\end{array}$} & Yes & 59 & 59.0 \\
\cline { 2 - 4 } & No & 41 & 41.0 \\
\hline
\end{tabular}




\begin{tabular}{|c|c|c|c|}
\hline \multirow{2}{*}{$\begin{array}{c}\text { SnackJ } \\
\text { Not l.1 unJ:ry }\end{array}$} & Yo & 58 & 58.0 \\
\cline { 2 - 4 } & No & 42 & 42.0 \\
\hline $\begin{array}{c}\text { IVhlleWatebln : } \\
\text { TV }\end{array}$ & Yes & 73 & 73.0 \\
\cline { 2 - 4 } & No & 27 & 27.0 \\
\hline \multirow{2}{*}{$\begin{array}{c}\text { Eat Vuy Fasl } \\
\text { fJrcfrr } \\
\text { U omemade }\end{array}$} & No & 41 & 41.0 \\
\hline \multirow{2}{*}{$\begin{array}{c}\text { Enrci.st: } \\
\text { Yc> }\end{array}$} & No & 76 & 59.0 \\
\hline \multirow{2}{*}{\begin{tabular}{c} 
E:urdse Per Wtek \\
\cline { 2 - 4 }
\end{tabular}} & No & 24 & 76.0 \\
\hline Extrrlse & 20 & 42 & 24.0 \\
\hline Ouration & $>20$ & 63 & 580 \\
\hline
\end{tabular}

Table 1.2: Categorizing study sample into groups according to some given variables

Regarding weight categories, 52\% of participants are of a normal weight category at level 5-6. Obesity is only seen among level $3-4$ "12\%" (Figure 1). 26\% of participants who always -usually eat breakfast are of an overweight category. Obesity is seen in both groups, there's no relation between eating breakfast and BMI (Figure 2).

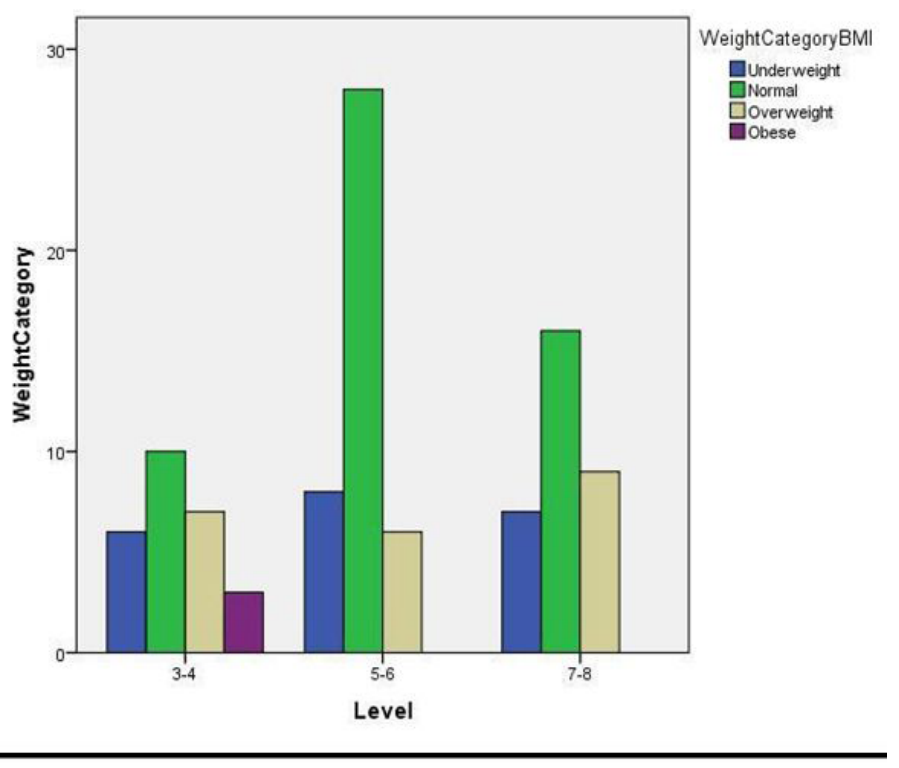

Figure 1: BMI distribution among levels

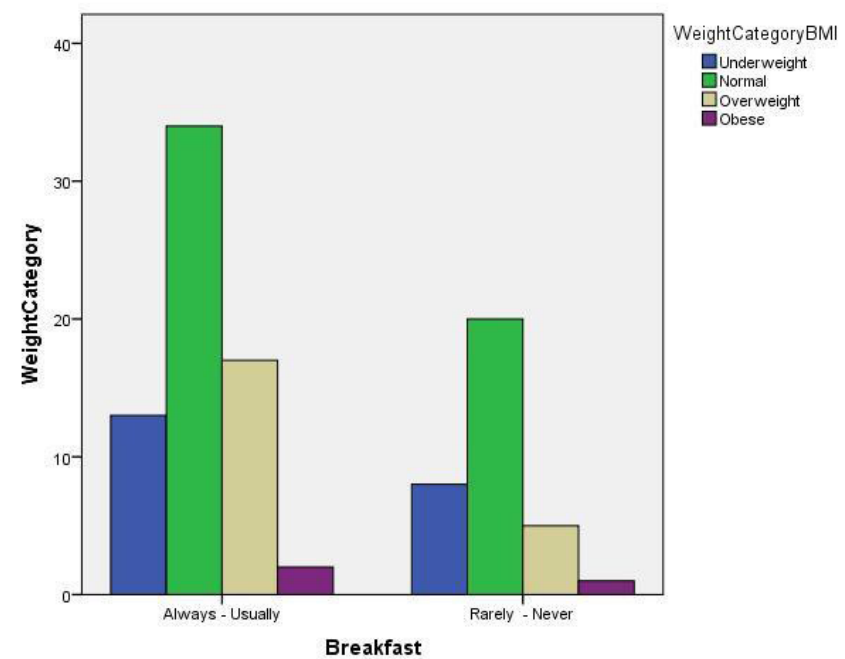

Figure 2: Breakfast and BMI 
$54 \%$ of participants who eat 1-3 meals are of a normal weight category (Figure 3). A special diet is used by only $7 \%$ of participants (Table 2).

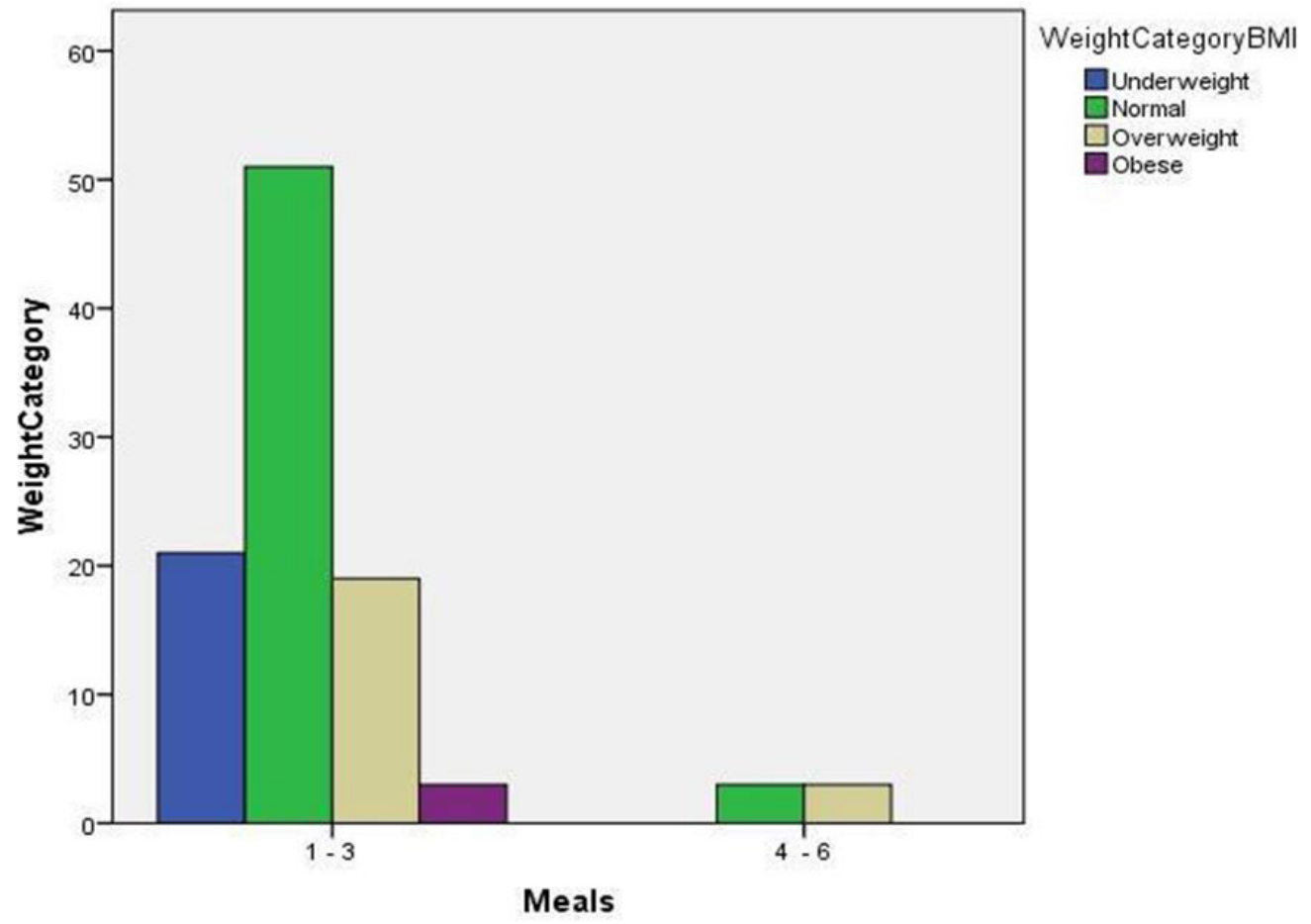

Figure 3: BMeals and BMI

\begin{tabular}{|r|r|r|r|r|r|}
\hline \multirow{2}{*}{ Special Diet } & \multicolumn{4}{|c|}{ Weight Category BMI } & \multirow{2}{*}{ Total } \\
\cline { 2 - 5 } & Underweight & \multicolumn{1}{|c|}{ Normal } & \multicolumn{1}{c|}{ Overweight } & Obese & 7 \\
\hline Yes & 1 & 2 & 3 & 1 & 93 \\
\hline No & 20 & 52 & 19 & 2 & 100 \\
\hline Total & 21 & 54 & 22 & 3 & 7 \\
\hline
\end{tabular}

Table 2 : Special diets and BMI

$24 \%$ of participants who're Always - Usually eating fruits and vegetables are overweight, while $49 \%$ of them have a normal weight (Table 3).

\begin{tabular}{|c|c|c|c|c|c|}
\hline \multirow{2}{*}{$\begin{array}{c}\text { Eating fruits/ } \\
\text { vegetables }\end{array}$} & \multicolumn{4}{|c|}{ Weight category BMI } & \multirow{2}{*}{ Total } \\
\cline { 2 - 5 } & underweight & normal & overweight & obese & \multirow{2}{*}{$\mathbf{7 0}$} \\
\hline $\begin{array}{c}\text { Always/ } \\
\text { Usually }\end{array}$ & $24 \%$ & $49 \%$ & $\mathbf{2 4} \%$ & $\mathbf{3} \%$ & 30 \\
\hline Rarely/Never & $13 \%$ & $67 \%$ & $17 \%$ & $3 \%$ & 30 \\
\hline
\end{tabular}

Table 3: Fruits/vegetables and BMI

Regarding drinking sodas, 67\% of obese participants don't drink sodas (Figure 4). 32\% of who eat emotionally are overweight/ obese. $15 \%$ of those who don't eat emotionally are overweight/obese (Figure 5).
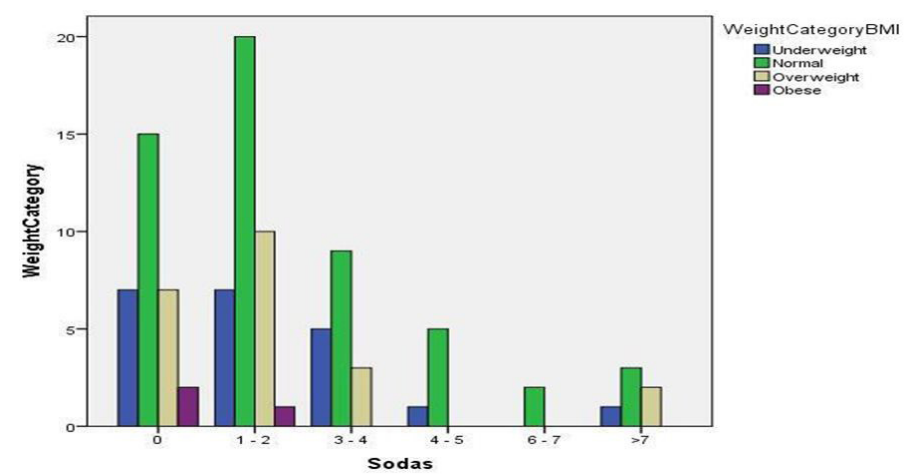

Figure 4: Drinking sodas and BMI 


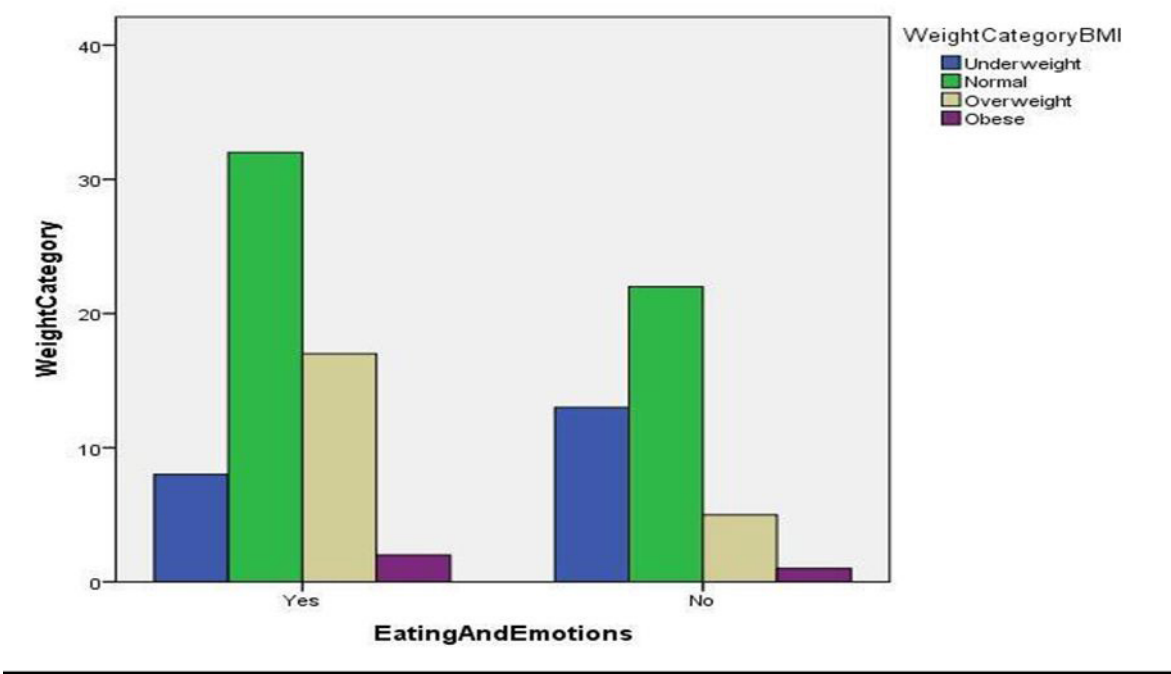

Figure 5: Emotions and BMI

$72 \%$ of overweight/obese participants snack when they're not hungry, $28 \%$ of them don't snack (Figure 6). On the other hand, $73 \%$ of underweight/normal participants and $27 \%$ of overweight/obese participants eat while watching TV (Figure 7 ). There's variation, but the difference is not statistically significant.
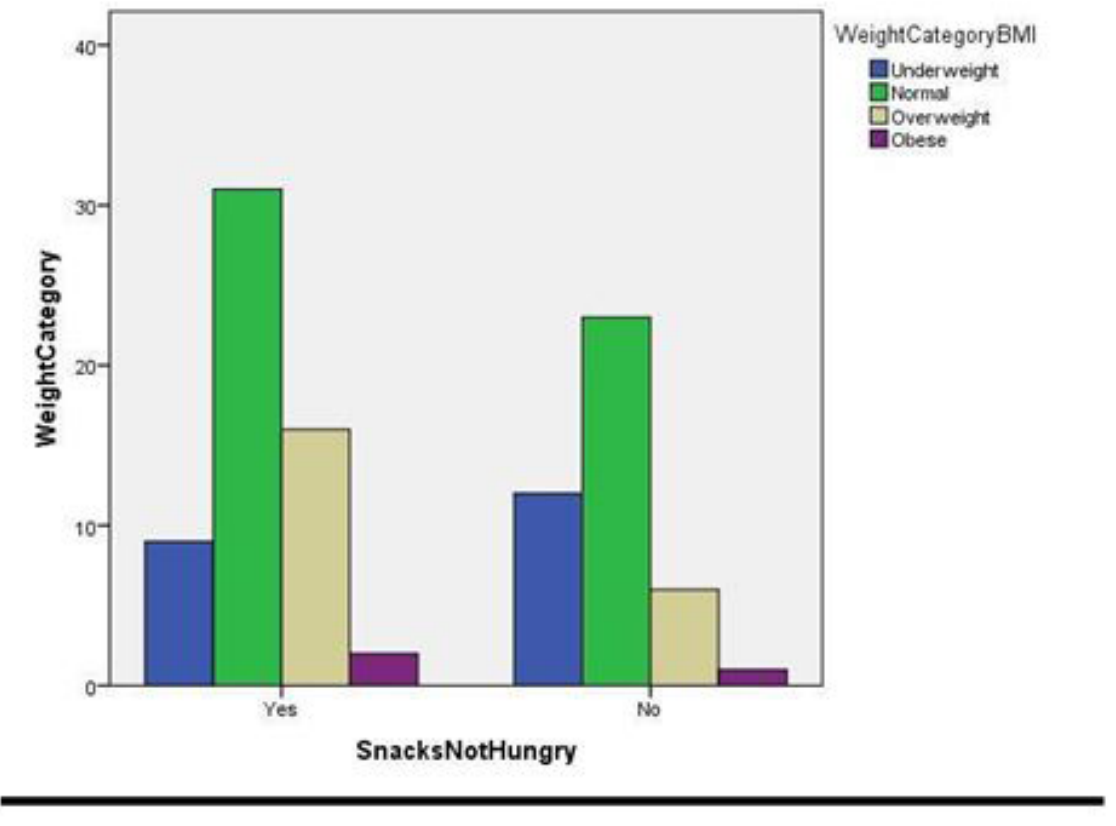

Figure 6: Snacks and BMI

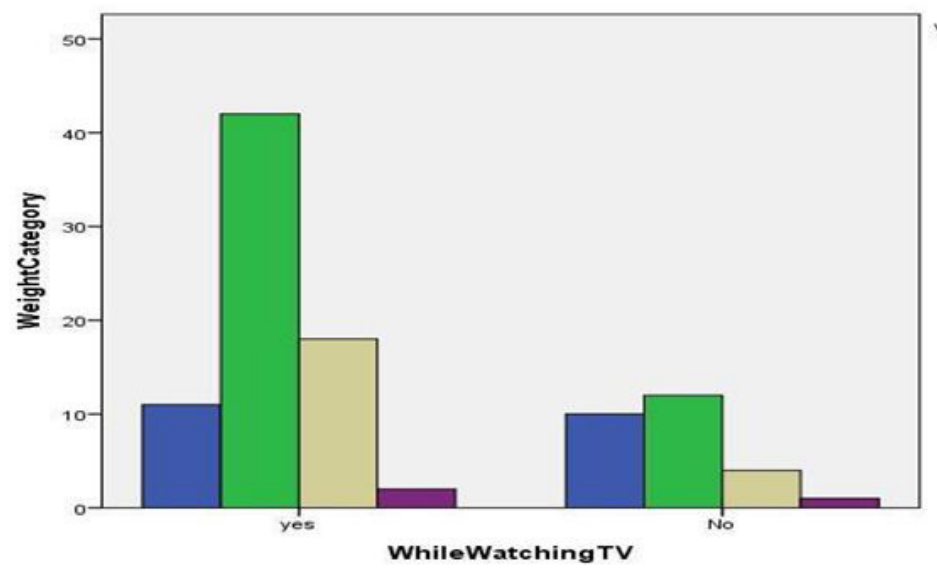

WeightCategoryBM Qunderweight Goverweight

Figure 7: Watching TV and BMI 


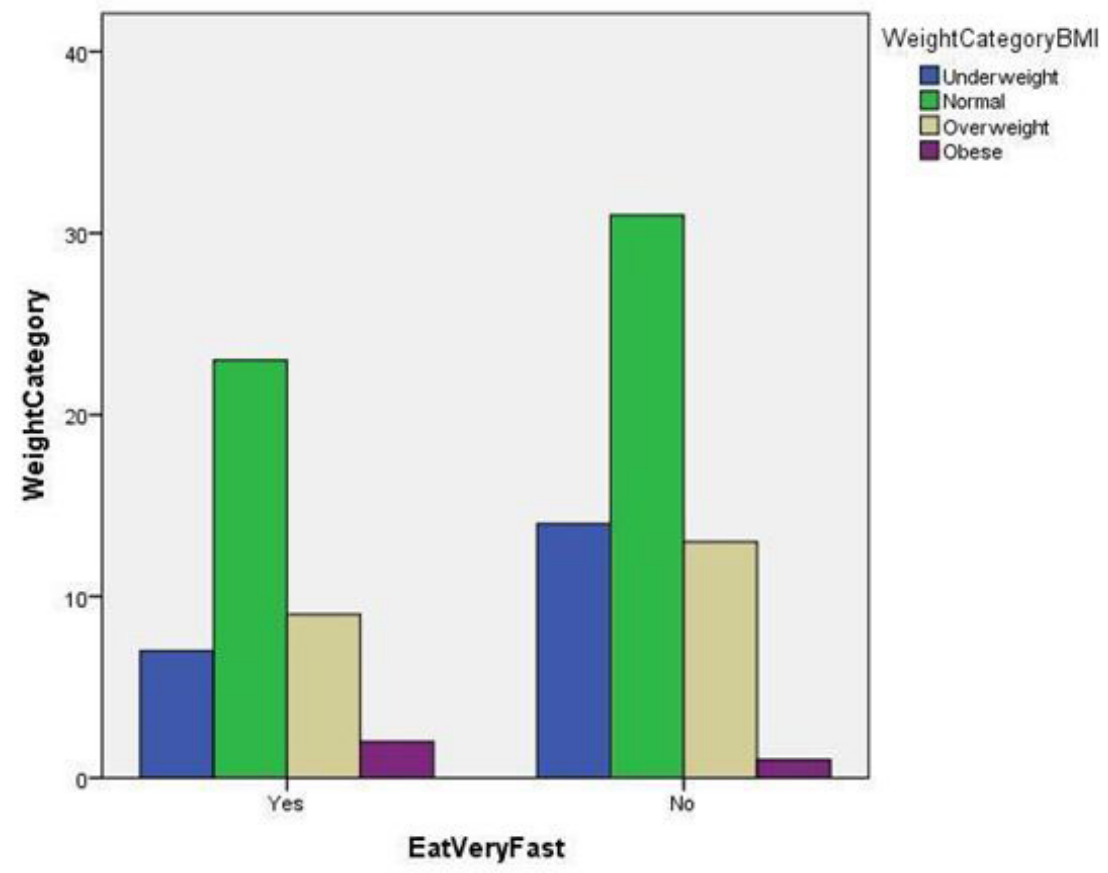

Figure 8: Fast eating and BMI

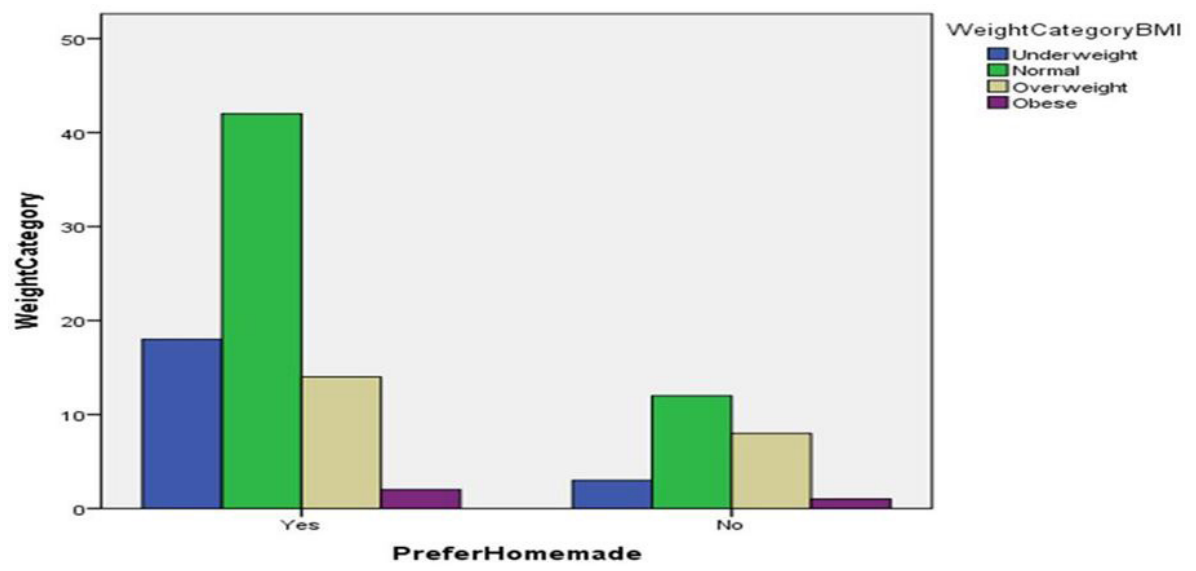

Figure 9: Homemade food and BMI

$52 \%$ of normal weight participants exercise, and $48 \%$ of them don't (Figure 10 ) whereas $35 \%$ of normal weight participants exercise 3 times or more a week. No obese participants are seen in those who exercise 3 times a week or more. 60\% of overweight/obese participants exercise 2 times or less a week. There's a strong relation between the amount of exercise and ideal BMI (Figure 11). $33 \%$ of normal weight participants exercise more than 20 minutes weekly, while $67 \%$ exercise less than 20 minutes weekly (Figure 12).
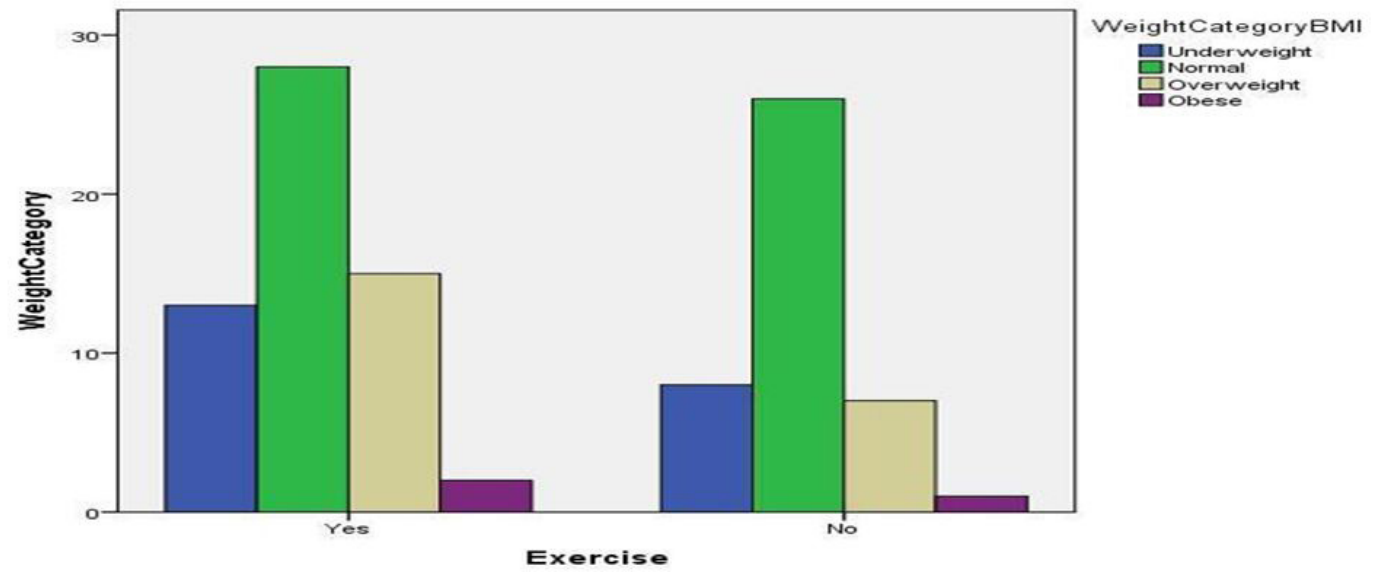

Figure 10: Exercise and BMI 

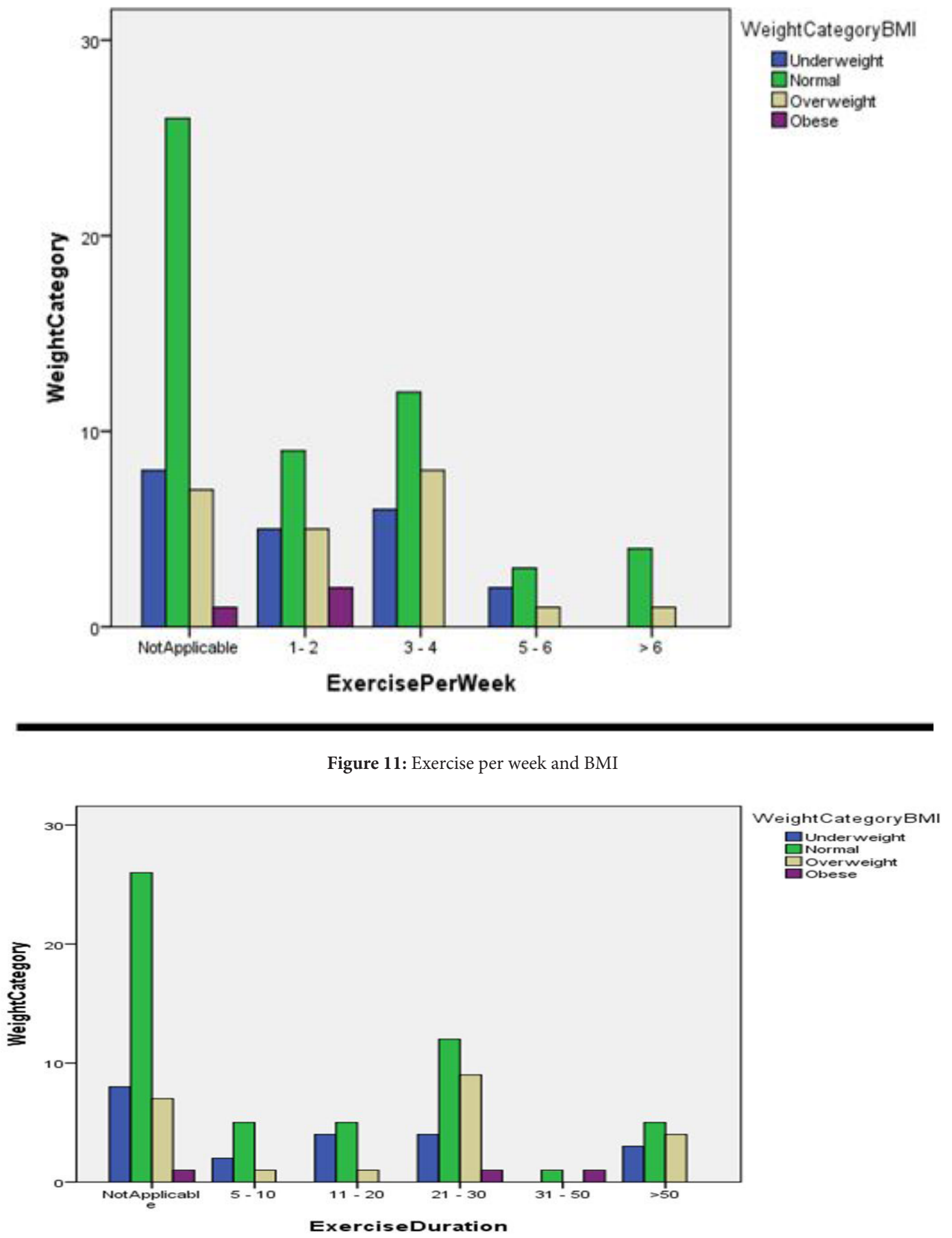

Figure 12: Exercise duration and BMI

\section{Discussion}

\section{Major Findings}

The purpose of the study was to find the relation between exercise and eating habits to BMI among participated medical students. The major findings of the study suggested the following: (1) only exercise had a strong relation to the ideal BMI; (2) comparing with the other factors, fast eating was found to be highly associated with obesity.

\section{Comparisons with Previous Work}

As the result showed, eating fruits and vegetables had a little association with BMI, fruit and vegetable intake has many benefits, such as contributing micronutrients, fiber, and phytochemicals, but increasing their uptake has no weight change (up or down) on average. The same finding was reported in a study conducted at University of Alabama [13]. In addition to that, the study result showed no association between emotions and BMI, a similar study conducted at University of Würzburg found that it remains 
difficult to predict how emotions affect eating, some people eat less when they are faced with emotional troubles, but other ones don't. So the exact underlying mechanism is still unclear [14]. This study result showed that there was no relation between eating while watching TV and high BMI, which was in contrast to the result of Toronto University that found those who watched TV while eating consumed an average of 228 calories more than those who did not and have high BMI. This difference in the results may be related to many factors such as the educational level of medical students and their understanding of eating control even while watching TV [15].

As the result showed, there was an association between obesity and fast eating. A Recent American research showed that overweight men and women took in fewer calories when they slowed their normal eating pace. And a recent Japanese study concluded that eating more slowly resulted in feeling full sooner and thus eating fewer calories at mealtime. Normally, it takes approximately 20 minutes from the time of start eating for the brain to send out signals of fullness. Leisurely eating allows ample time to trigger the signal from the brain that the person is full. And feeling full translates into eating less [16].

Also, a study conducted at Columbia University showed a similar result, that fast food consumption has no direct effect on BMI. Yet, most of the existing evidence on the causal link between the supply of fast food and incidence of obesity is difficult to interpret because it is based on correlations. Since consumers have access to unhealthy food from many sources, it is possible that obesity rates would be higher even in the absence of fast food restaurants [17].

The result of this study showed that there was a strong relation between regular physical activity and normal BMI, which is in line with the result of a prospective cohort study conducted in Boston which found that women who were in the normal weight range at the start of the study needed the equivalent of an hour a day of physical activity to stay at a steady weight. This supports the result where there was a strong relation between exercise and ideal BMI. Physical activity can help maintaining the BMI by both burning calories and building muscle [18].

\section{Conclusion}

This study revealed a strong association between physical activity and BMI. The BMI tend to be better (normal) among those who practice regular exercise. Fast eating was found to be associated with obesity.

The study didn't show any association between BMI and consuming vegetables, fruits, watching TV while eating and emotions.

\section{Recommendations}

According to this study, the following is recommended:

- Regular exercise and walking at least 20 minutes 3 times per week can help to achieve ideal BMI.

- Practicing exercise is the best way to achieve and maintain ideal BMI.

- Avoid fast eating.

\section{References}

1. Benazeera B, Chauhan U (2014) Association between eating habits and body mass index (BMI) of adolescents. Int J Med Sci Public Health 3: 940-3.

2. Gunes FE, Bekiroglu N, Imeryuz N, Agirbasli M (2012) Relation between eating habits and a high body mass index among freshman students: A Cross-Sectional Study. J Am Coll Nutr 31: 167-74.

3. Al-Rethaiaa AS, Fahmy AE, Al-Shwaiyat NM (2010) Obesity and eating habits among college students in Saudi Arabia. Nutr J 9: 10.1186/1475-2891-9-39.

4. Alfawaz H (2012) Relationship between fast food consumption and BMI among university female students. Pak J Nutr 11: 406-10.

5. Smith BJ, Phongsavan P, Havea D, Halavatau V, Chey T (2007) Body mass index, physical activity and dietary behaviors among adolescents in the Kingdom of Tonga. Public Health Nutr 10: 137-44.

6. Silliman K, Rodas-Fortier K, Neyman M (2004) A survey of dietary and exercise habits and perceived barriers to following a healthy lifestyle in a college population. Calif J Health Promot 2: 10-9.

7. Racette SB, Deusinger SS, Strube MJ, Highstein GR, Deusinger RH (2005) Weight changes, exercise, and dietary patterns during freshman and sophomore years of college. J Am Coll Health 53: 245-51.

8. James KJ (2010) Assessing Dietary Intake, Eating and Exercise Attitudes and Fitness Levels in College- Aged Students. Nutrition \& Health Sciences Dissertations \& Theses, USA.

9. Enes C, Slater B (2013) Variation in dietary intake and physical activity pattern as predictors of change in body mass index (BMI) Z-score among Brazilian adolescents. Rev Bras Epidemiol 16: 493-501.

10. O’Dea JA, Amy NK (2011) Perceived and desired weight, weight related eating and exercising behaviors, and advice received from parents among thin, overweight, obese or normal weight Australian children and adolescents. Int J Behav Nutr Phys Act 8: 10.1186/1479-5868-8-68.

11. Haerens L, Vereecken C, Maes L, De Bourdeaudhuij I (2010) Relationship of physical activity and dietary habits with body mass index in the transition from childhood to adolescence: a 4-year longitudinal study. Public Health Nutr 13: 1722-8.

12. Kelishadi R, Ardalan G, Gheiratmand R, Gouya MM, Razaghi EM,et al. (2007) Association of physical activity and dietary behaviors in relation to the body mass index in a national sample of Iranian children and adolescents. Bull World Health Organ 85: 19-26.

13. Kathryn AK, Andrew WB, Michelle MBB, Shikany JM, Mattes RD, et al. (2014) Increased fruit and vegetable intake has no discernible effect on weight loss: a systematic review and meta-analysis. Am J Clin Nutr 100: 567-76.

14. Macht M (2008) How emotions affect eating: a five-way model. Appetite 50: 1-11. 
15. Bellissimo N, Pencharz PB, Thomas SG, Anderson GH (2007) Effect of Television Viewing at Mealtime on Food Intake After a Glucose Preload in Boys. Pediatr Res 61: 745-9.

16. "Does Slower Eating Rate Reduce Food Intake? Results of an Empirical Test," presented at annual meeting of the North American Association for the Study of Obesity, Las Vegas. 2004: 14-18, USA.

17. Janet C, Stefano D, Enrico M, Pathania V (2009) The Effect of Fast Food Restaurants on Obesity. Am Eco J Eco Polic 2: $32-63$.

18. Lee IM, Djoussé L, Sesso HD, Wang L, Buring JE (2010) Physical activity and weight gain prevention. JAMA 303: $1173-9$.

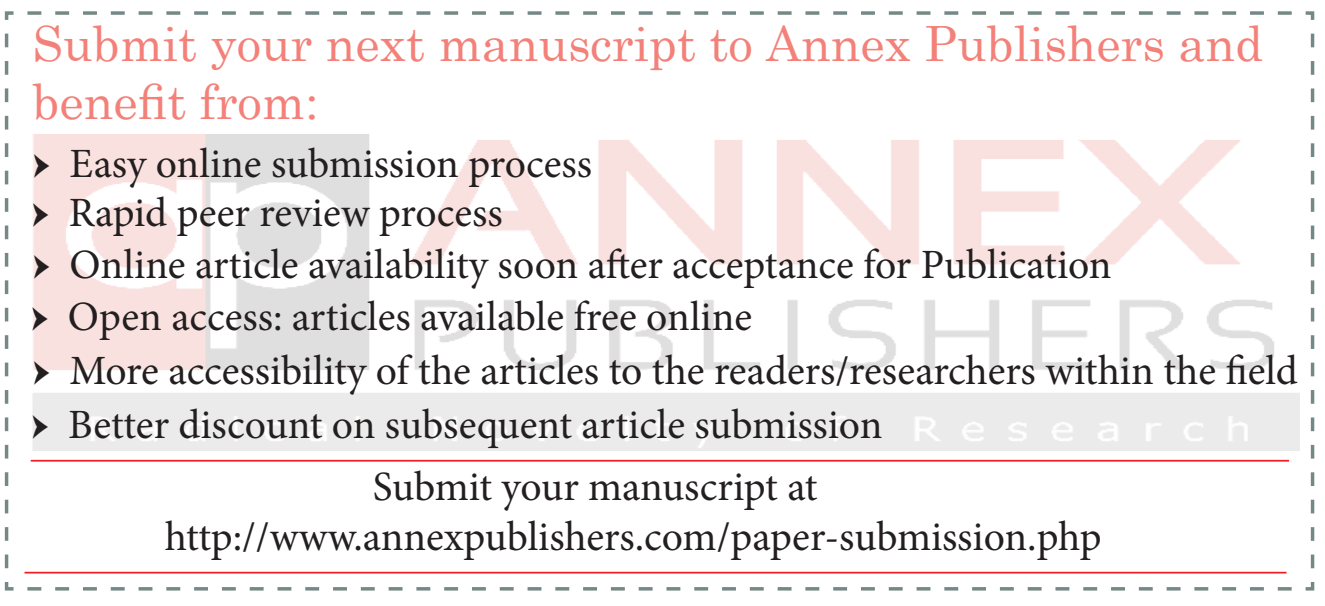

